\title{
TRAJETÓRIA DA BIBLIOTECA PUBLICA NO MARANHÃO PROVINCIAL
}

\author{
César Augusto Castro \\ Ana Luiza Ferreira Pinheiro
}

\begin{abstract}
Resumo
Análise da trajetória da Biblioteca Pública do Maranhão desde a sua criação em 1829, no Convento do Carmo, até 1889. Formada inicialmente com o apoio dos homens da elite e de populares, desde a sua gênese até o advento da República, a Biblioteca Pública passou por diversas situações, ora de pleno abandono e ora de apogeu. Nesse particular, resgata-se o ofício do bibliotecário e diretores que fizeram brotar as iniciativas para a "socialização" do livro e da leitura no Maranhão oitocentista. A partir desta pesquisa histórica, pode-se compreender o papel que a mesma assumiu na formação da intelectualidade maranhense e na constituição do campo educacional, sendo o espaço privilegiado de convergência de idéias e saberes de professores, jornalistas, políticos o que ensejou na fundação da Oficina dos Novos, Sociedade Cívica das Datas Nacionais, Academia Maranhense de Letras, jornais, revistas e outras ações que favoreceram a São Luis ser denominada de Atenas Brasileira. Para o resgate dessa trajetória pesquisou-se em fontes como jornais, relatórios e falas de Presidentes de Província, legislação, iconografias entre outros documentos que possibilitaram traçar os seus caminhos e descaminhos, na constituição do seu acervo e da sua estrutura física. Conclui-se que esta pesquisa ao revisitar o passado revela as contradições na formação das bibliotecas públicas e abre-se um debate para a necessidade de investigações que busquem fazer emergir a história e memória dessas instituições no Brasil.
\end{abstract}

\section{Palavras-chave}

Biblioteca pública do Maranhão; Maranhão provincial; Biblioteca Pública Benedito Leite.

\section{PATH OF THE PUBLIC LIBRARY IN PROVINCIAL MARANHÃO}

\begin{abstract}
Analysis of the path of Public Library of Maranhão since its creation in 1829, in Carmo Convent, to 1889. It was formed initially with the support of the elite and the ordinary people, since its genesis until the advent of Republic, the Public Library has been put under different situations, sometimes of complete abandon and others of peak. In this matter, it is rescued the work of librarians and directors that have created the initiatives for the 'socialization' of the book and reading in Maranhão in the 80's. From this historical research it is possible to comprehend the role that it has taken in the background of maranhense intelectuality and in the constitution of the educational field, it has been the privileged space of convergent ideas and knowledge of teachers, journalists and politicians that encouraged the foundation of the Oficina dos Novos (Workshop of Novice), Sociedade Civica das Datas Nacionais (Civic Society of National Dates), Academia Maranhense de Letras ( Maranhense Academy of Letters), newspapers, magazines and other actions which helped São Luis to be named as Brazilian Athens. For the rescue of this path, it was made researches on sources as such: newspapers, reports and speeches of Presidents of the Province, legislation, iconography among other documents that made possible to find its ways and non-ways, in the constitution of its heritage and its physical structure. It is concluded that this research by looking back to the past reveals the contradictions in the formation of public libraries and it also opens a debate to the necessity of investigations that bring out the history and memory of these institutions in Brazil.
\end{abstract}

\section{Key-words}

Public library of Maranhão; Provincial Maranhão; Benedito Leite Public Library

(c) Revista Digital de Biblioteconomia e Ciência da Informação, Campinas, v. 4, n. 1, p. 38-50, jul./dez. 2006 - ISSN: 1678-765X. 


\section{INTRODUÇÃO}

Ao longo da vida, armazenamos cenas e fatos que marcaram e ficaram para trás e nem sempre fazemos o seu resgate, ao contrário, a cada instante que vivemos o presente, deixamos de lado fatos, contextos, instituições, relações de vida e de trabalho. Um olhar para o passado permite-nos entender o que somos. No âmbito deste texto, a nossa proposta foi resgatar a história da biblioteca pública na Província do Maranhão, no período de 1838, quando da sua criação até o advento da República em 1889, descrevendo seu cotidiano e os enfretamentos econômicos, sociais, culturais, educacionais e políticos pelos quais a mesma passou neste período. A busca pela descoberta daquilo que teria acontecido com essa instituição foi um “processo de urdidura, montagem, seleção e exclusão” (PESAVENTO, 2003, p. 53) de fontes que propiciam a emersão da Biblioteca Pública no Maranhão oitocentista. Ao mesmo tempo em que este estudo, em uma perspectiva ampla, traz para o campo da Biblioteconomia a possibilidade de preencher uma lacuna histórica sobre as instituições bibliotecárias no Brasil.

Portanto, para realização deste estudo, mergulhamos na documentação primária manuscrita, nos jornais, na legislação, nos livros e outras fontes armazenadas no Arquivo Público do Estado do Maranhão e na Biblioteca Pública Benedito Leite. Os relatórios de Presidente de Província e os ofícios dos "bibliotecários" e dos diretores que estiveram à frente da biblioteca representam a espinha dorsal do estudo. Por fim, ressaltamos que esta pesquisa integra um conjunto de investigações acerca da "História, memória das instituições de educação e das práticas de leituras” desenvolvidas no Departamento de Biblioteconomia da Universidade Federal do Maranhão, sob a Coordenação do Prof. César Augusto Castro.

\section{A CRIAÇÃO DA BIBLIOTECA PÚBLICA DA PROVÍNCIA DO MARANHÃO}

A criação de uma biblioteca para a Província do Maranhão foi proposta na Assembléia Legislativa na sessão de 08 de julho de 1826 por Dr. Antonio Pedro da Costa Ferreira, Membro do Conselho Geral de Província, mas somente em 1829, foram tomadas as medidas para concretização dessa idéia, que contaria apenas com um oitavo das sobras do 
orçamento dos cofres do governo; entretanto, D. Pedro I não autorizou por achar a idéia extravagante. Para realizar seu intento, Costa Ferreira buscou apoio dos intelectuais locais como Antonio Ennes de Souza e a solução encontrada foi empreenderem “ [...] uma subscrição popular e voluntária, para obtenção dos meios necessários [...]” (MORAES, 1973, p. 16). Para isso, contaram a princípio com a Câmara Municipal de São Luís, que ficou com a missão de tornar concreta a idéia de se ter uma biblioteca na Província do Maranhão. Com esta finalidade nomeou uma comissão “[...] composta pelos vereadores João Gualberto da Costa e Manoel Pereira da Cunha, a qual, com o auxílio do Município, deu execução às ordens do Governo” (VIVEIROS, 1960, p. 151).

Situada em uma das salas da parte superior do Convento do Carmo, em 1829, foi inaugurada a Biblioteca Pública do Maranhão e aberta ao público em 1831 com 1.448 volumes adquiridos com o dinheiro arrecadado da subscrição popular e com doações dos ilustres ludovicenses, cuja guarda e conservação do acervo estaria a cargo do diretor, de um guarda e de um servente que juntos estabelecem o seu primeiro Regulamento que dispunha sobre o horário do funcionamento e as condições de admissão de pessoas. Em relação ao horário, a Biblioteca estaria aberta todos os dias das 8 às 14 horas, exceto domingos e feriados. Eram proibidas conversas em voz alta e os passeios no seu interior, quem infringisse esse artigo poderia ser expulso. Assim, como pessoas adequadamente vestidas poderiam freqüentá-la.

Serão admitidas todas as pessoas que se apresentarem decentemente vestidas, franqueadose-lhes os livros, que pedirem, pennas e tinta; nenhuma das pessôas admitidas poderá tirar os livros das Estantes ou restituilos à ellas, devendo para isso dirigir-se ao Contínuo, à quem pelo Art.3 incumbe esse trabalho. Também não se poderá emprestar livro algum para fora da Biblioteca”. (MARANHÃO, 1835, grifo nosso).

Fica evidente, portanto, que a biblioteca, assim, como outras instituições maranhenses, era restrita aos homens brancos de poder aquisitivo e, principalmente, que soubessem ler e escrever. Privilégios de poucos em todas as províncias, mesmo as mais desenvolvidas, como a do Maranhão.

O material de leitura colocado à disposição dos poucos leitores era vigiado e controlado por ordem de Vicente Tomaz Pires de Figueiredo Camargo, Presidente da Província, que

(c) Revista Digital de Biblioteconomia e Ciência da Informação, Campinas, v. 4, n. 1, p. 38-50, jul./dez. 2006 - ISSN: 1678-765X. 
julgava que em sendo uma instituição dedicada a educação dos jovens os livros deveriam preservar os princípios religiosos e contribuir na formação de homens bons e probos. Os contrários deveriam ser expurgados por uma comissão criada com esta finalidade. Isso se dava pelo fato da Biblioteca funcionar contígua ao Liceu Maranhense, servindo como auxiliar às aulas nele ministradas.

O controle sobre as materialidades de leitura e as dificuldades para ampliar o acervo ou fazer as reformas precisas na Biblioteca esbarravam na crise econômica, política e social desencadeado com a Balaiada e, principalmente com o empobrecido da sociedade endinheirada local com a desvalorização do algodão maranhense no mercado internacional. Neste quadro, calavam-se os comentários sobre a Biblioteca ou qualquer apoio financeiro, físico e material a mesma. Na década de 40, continuava como um lugar sombrio, paredes escuras, estantes abarrotadas de livros que dividiam espaço com outros objetos escolares, como lousas e carteiras. Situação agravada com a instalação do museu de história natural, que também funcionava no interior da Igreja do Carmo. Sob um ponto de vista social era de grande importância para a província possuir uma biblioteca e um museu, entretanto, nenhum dos dois tinha significado, muito pelo contrário, estavam fadados à ruína.

Em 1850, a Biblioteca teve alguns reparos em seu prédio. Para Herculano Ferreira Pena, Presidente da Província, as providências para melhoria da Biblioteca eram simples e fáceis, e uma delas seria colocá-la sob a responsabilidade da Inspetoria Pública, fato que propiciou a Biblioteca ser anexada ao Liceu Maranhense. Esta anexação não significou que a mesma tivesse um papel de destaque para o ensino secundário, muito pelo contrário, continuou sem estrutura, faltava-lhe um bom edifício, estantes e livros, ou seja, faltava-lhe vida, ou seja, “ [...] nenhum augmento tem tido no número de volumes, a não ser o de alguns livretes e colecções de leis geraes, achando-se trancadas muitas obras que possue, por haverem sido separados os volumes arruinados [...]” (RELATÓRIO, 1859, p. 14, grifo nosso).

Para Ambrosio Leitão da Cunha (1865), de nada adiantaria suprir a Biblioteca com livros e embelezá-la com a valiosa doação de dezesseis retratos a óleo, doados pela viúva de Antonio Gonçalves Dias, se ela continuava no mesmo lugar, era necessário mudá-la para outro edifício que pudesse lhe proporcionar conforto, além disso, o horário de 
funcionamento precisava ser revisto, do contrário de nada adiantaria ter essa instituição na Província.

[...] duas são as causas, que tem contribuído para isso; a primeira - o tempo em que está aberta a biblioteca - das 9 horas da manhã as 2 da tarde, e que não convida a concorrência por que a maior parte das pessoas amigas da leitura estão nas suas ocupações diárias; a segunda - a pouca ventilação, que há na sala do estabelecimento, do que resulta a propagação dos insectos, que tem destruído grande parte dos livros variados e excellentes, que a principio forão alli collecionados” (CUNHA, 1865, p. 15).

O que a Biblioteca não imaginava é que estava preste a mudar de endereço, pois a sua ruína era evidente “[...] com o decorrer do tempo essa situação não mudou para melhor, senão que se agravou consideravelmente. Pelo que se conclui de consulta a diversas fontes, continuou para a Biblioteca uma época de franca decadência e abandono [...]” (MORAES, 1973, p. 17). Desse modo, durante o governo de Lafayette Rodrigues Pereira, em 1866, a Biblioteca é transferida do Convento do Carmo para o Instituto Literário Maranhense.

Com o regulamento que tem, no edifício em que está é desprovida de livros, como se acha, a biblioteca continua a ser de prefeita inutilidade para o público. Urge, pois, mudála para casa apropriada, enriquecê-la de grande cópia de obras de todos os ramos de conhecimento humanos e dar-lhe regimem, de maneira que esteja ella aberta nas horas, em que pode ser maior a afluência dos estudiosos (RELATÓRIO, 1866, p. 23).

O Instituto Literário, como a Biblioteca, ocupava o Convento do Carmo, e fora criado em 25 de março de 1865, sendo dirigido por Antonio Henrique Leal e Antonio Rego com o objetivo de realizar estudos em história, geografia, etnografia do Maranhão e expandir a instrução; além disso, uma das suas funções seria “[...] criar bibliotecas e promover publicações de obras úteis” (VIVEIROS, 1957, p. 153).

Com esta mudança ocorre um aumento considerável do seu acervo, fruto de compras e doações e alguns remanescentes da "antiga biblioteca” como a 950 volumes e pinturas a óleo de Antonio Gonçalves Dias e 300 volumes doados pela viúva de Raimundo Teixeira Mendes, além das doações dos intelectual-protetores Antonio Henrique Leal e Antonio Rego, que "deram uma nova feição e procedeu a primeira catalogação regular deste estabelecimento[...]” (PERDIGÃo, 1915, p. 5). Por conta destas doações, a Biblioteca passou a dispor de um acervo composto de obras literárias e científicas colocadas a disposição no salão de leitura. Este salão funcionava na antiga sala onde esteve a Biblioteca

(c) Revista Digital de Biblioteconomia e Ciência da Informação, Campinas, v. 4, n. 1, p. 38-50, jul./dez. 2006 - ISSN: 1678-765X. 
quando da sua criação. Não há registros que expressem a freqüência no local, o que se sabe é que ele permaneceu até a extinção do Instituto, em 1873. Entretanto, esse período de prosperidade não se estenderia por muito tempo, pois:

Infelizmente, durante essa organização, adquirido o Dr. Henrique Leal atroz enfermidade, que o obrigou a abandonar sua obra antes de terminada, e d'ahi em diante, a Bibliotheca foi sendo esquecida e caindo em decadência até que passou novamente a ser administrada pelo governo da província, com o que também não prosperou muito (PERDIGÃO, 1915, p. 5).

Com a doença de Henrique Leal, a Biblioteca perdeu um de seus protetores e voltou ao poder do governo, que, sem demora, tratou de isentar-se da responsabilidade e procurou outra instituição que pudesse assumí-la, como a Sociedade Onze de Agosto. Tratava-se de uma sociedade protetora da instrução pública que tinha como objetivo principal favorecer a educação do povo gratuitamente, principalmente a dos operários maranhenses, através de cursos noturnos em que se ensinavam primeiras letras, aritmética, geometria, mecânica, desenho linear aplicado à indústria e às artes, física, química, economia, política econômica e agricultura.

Essa Sociedade, através da Lei N 991, recebeu a Biblioteca Pública, deixando-a permanecer até 1880, um período que correspondeu há oito anos. Nesse período foi estabelecido um outro regulamento que determinava que em caso da destituição da Biblioteca todas as doações seriam repassadas aos doadores e seus herdeiros. No caso de alguma sociedade querer unir o seu acervo ao da Biblioteca, teria que obedecer ao seguinte artigo e incisos:

\footnotetext{
Art. 9 Se alguma sociedade possuidora de livros quizer unil-os aos da Biblioteca, poderá fazel-o sob as seguintes considerações:

$\S 1$ Os livros serão restituídos em qualquer tempo.

$\S 2$ A reunião dos livros só dara o direito de votar aos membros directores da sociedade.

§ 3 A sociedade contribuirá para a Bibliotheca com a anuidade de dez mil reis.

$\S 4$ Se a sociedade não cumprir o disposto no § 3, seus representantes ficarão suspensos do direito de votar (MARANHÃO, 1872 apud ALMEIDA, 1872, p. 374).
}

Este Regulamento estabelece pela primeira vez uma sistemática para empréstimo domiciliar de livros, que se constituía ao mesmo tempo, em uma forma de lucro financeiro à Biblioteca, posto que, o leitor ao tomar um livro deveria assinar um recibo e fazia um depósito junto ao bibliotecário no valor equivalente ao preço do livro, esse valor seria 
resgatado no ato de devolução. Para isso, todas as obras continham os seus respectivos valores. Por cada livro emprestado o leitor pagaria uma quantia a ser revestida para compra de outros livros.

Entretanto, essa boa fase da Biblioteca não durou muito, posto que, a Sociedade Onze de Agosto, existiu por dez anos, pois foi acometida por dificuldades financeiras que culminaram na venda do prédio para o governo, única solução encontrada para saudar sua dívida. Além do que este prédio era cobiçado pela Assembléia Provincial que se reunia na Catedral da Sé, devido à falta de uma sede e “[...] a escola 'Onze de Agosto’, porém, a seu tempo mostrava-se um edifício nobre e grandioso. Era muito para a Biblioteca e aulas de primeiras letras. Não era demais para um parlamento” (FERNANDES, 1929, p. 333).

Parece que o destino da Biblioteca era ser errante, pois, por duas vezes havia mudado de lugar e se preparava para mais uma mudança, para a Catedral da Sé, entretanto, esta parecia ser a pior de todas, “[...] o começo da destruição” (ARANHA, 1886, p. 4). Era difícil a sua situação depois de ter passado por uma fase próspera na Sociedade, estava outra vez a revelia sem poder imaginar seu próprio destino, além disso, a maneira como foi feita a transferência mostrou que a nova fase que viveria não parecia ser benéfica.

\begin{abstract}
Durante três ou quatro dias assistio a população desta cidade um espetáculo contristador. Ao mesmo tempo em que uma dúzia de calcetas, guardadas por soldados, carregava em cestos. cofos e caixões, sem ordem nem methodo, os livros da bibliotheca, e outros tantos pedreiros metiam o alvião nas paredes e arrancavam as estantes, carapinas levantavam os estrados, deslocavam as mesas e preparavam a sala para receber os representantes da província. Os carregadores dos livros muitas vezes deixavam os caixões nas portas das quitandas, e, emquanto faziam sua libações, o moleque que passava subtraia um volume para divertir-se ou vender mais adiante. As ruas comprehendidas entre os dois edifícios, o que era despojado dos livros e os que os recebia, ficavam lastradas de estampas, mappas, jornaes e folhas de livros (ARANHA, 1886, p. 4).
\end{abstract}

Esta mudança não agradou aos administradores da Sé, pois seria a oportunidade de reinar a paz no prédio, pois durante muitos anos, tinham alojado a Assembléia Provincial e "não lhes era agradável receber os que chegavam, embora silenciosos e incapazes de perturbar o socego que n'aquelle jogar deve reinar” (ARANHA, 1886, p. 4). Por isso, solicitam, em 1884, que a mesma fosse transferida para o Convento do Carmo, lugar onde a sua história começou. Esta transferência não significou que o governo a quisesse de volta, ao contrário,

(c) Revista Digital de Biblioteconomia e Ciência da Informação, Campinas, v. 4, n. 1, p. 38-50, jul./dez. 2006 - ISSN: 1678-765X. 
ARTIGO

desde que foi criada sempre esteve sob a responsabilidade de outras instituições e as poucas vezes que a foi incluída no orçamento provincial, a quantia não era suficiente para sua manutenção. Instalada nesse local, seu estado era de incerteza, a Assembléia Provincial não lhe destinava recursos e não havia pessoas para abrir as suas portas, permaneceu, então, dois anos fechada. Em 1886, João Capistrano Bandeira de Mello, Presidente da Província, designou o engenheiro Francisco Antonio Brandão, o inspetor de Instrução Pública e o Comendador Themistocles da Silva Maciel Aranha para providenciarem a guarda dos livros, bem como o remanejamento para outro lugar, antes que ficassem totalmente arruinados.

Nesse ano o Tesouro Provincial despendeu 23:553\$00 reis para a compra de livros e assinatura de jornais e para outros serviços necessários para que fosse aberta ao público. Com a finalidade de avaliar o seu estado Themistocles Aranha ao visitá-la assim descreve o seu estado:

\footnotetext{
Mas, oh! que decepção” - o commendador, como pleno nipotenciario do governo, ahi chegando, nada encontrou do quer procurava - nem Bibliotheca, nem biliothecario, nem mesmo porteiro. Guiado pelo porteiro do Lyceu na ausência do porteiro da Bibliotheca, Temístocles Aranha penetrou nos claustros do velho convento do Carmo, onde viu estantes e mezas da antiga Biblliotheca e, em quarto escuro, amontoados confusamente, uma grande porção de livros” ( FERNANDES, 1929, p. 333).
}

O Convento do Carmo ainda guardava, nos seus claustros, vestígios da antiga biblioteca, onde haviam velhos livros depositados em prateleiras e espalhados pelo chão. Parece que a sua história repetia-se. O comendador Temístocles da Silva Maciel Aranha no seu relatório ao descrever o seu estado, afirma que "[...] ainda mais precipitada do que a anterior, pois as salas, (si salas são esses quartos), que deviam receber os livros, nem sequer estavam caiadas e ladrilhadas (ARANHA, 1886, p. 4). Todavia, por mais que fossem feitas reformas a sala onde funcionaria não passaria de um quarto escuro, sem ventilação e sem a menor condição de conservar um acervo. Diante disso, sugere ao governo o que lhe parecia uma solução mais sensata: 
Testemunhando diariamente a solicitude de V. Exc. empregada em todos os ramos do serviço público, animo-me a pedir a V.Exc. que faça uma visita à esse logar. Verá V, Exc. que em tudo que tenho dito não há menor exageração. Não se tendo faitro na ' Escola Onze de Agsoto’ as obras precisas para transformal-a em casa de parlamento, seria mais acertado adquirir uma casa para a Assembléia Provincial e voltar a Bibliotheca para a Escola, d'onde nunca deveria ter sahido. Mas, como para taos despezas não há verba no orçamento provincial e nem auctorização, pois no meu humilde parecer, devem ser entregues à inspectoria da instrução publica os restos dos 3812 volumes com que em 4 de abril de 1883 foi reaberta a malfadada bibliotheca provincial. (ARANHA, 1886, p. 4).

A intenção do comendador ao sugerir ao Presidente da Província que visitasse a Biblioteca era pertinente, pois achava que se o governo visse a situação poderia sensibilizar-se a fazer alguma coisa para salvá-la das traças, do desprezo, que desde a sua criação vinha passando. Uma outra solução seria a construção de um prédio para a Assembléia Provincial e ela retornaria para local onde havia funcionado a Sociedade Onze de Agosto, porém isso era uma utopia de entusiasta, pois a Assembléia não iria abrir mão do conforto de suas novas instalações. Outro empecilho foi a falta de verba do governo para construir um prédio à altura de um parlamento, dessa forma, não havia o que fazer, a situação continuaria a mesma.

Daí em diante, a Biblioteca foi esquecida completamente, a Província deixou de contemplála em suas leis orçamentárias e os presidentes nem a mencionavam em seus relatórios. A história da Biblioteca Pública Provincial do Maranhão chegava ao fim, pois com o seu acervo jogado na parte inferior do Convento do Carmo, aos poucos se deteriorava e a falta de verbas para restaurá-la, comprar novas obras, manter-se em funcionamento, deixava pouco a pouco de existir, até chegar o momento em que iria desaparecer por completo, e ao que tudo indica, não faria falta.

Com a proclamação da república, houve mudança na Biblioteca digna de nota que foi a sua denominação de Biblioteca Pública Provincial para Biblioteca Pública Estadual. 


\section{REFERÊNCIAS}

CUNHA,. A Biblioteca pública no cenário da sociedade da informação. Revista Biblos. v.15, n.4,p.67-76,abril, 2003.

FERNANDES, H. Administradores maranhenses: 1822-1928. São Luís, Imprensa Oficial, 1929.

HISTÓRIA da instrução pública no Maranhão. O Combate, São Luís, 10 abr. 1857.

MARANHÂO. Leis, Decretos, etc. Regimento da Biblioteca. SNT, 12p.

MARQUES, C. A. Dicionário histórico-geografico da Província do Maranhão. São Paulo: SUDEMA,1970.

MORAES, J. Guia histórico da Biblioteca Pública Benedito Leite. São Luís: FUNC, 1973.

OLIVEIRA, A. A. Conversas públicas na Escola Normal. Maranhão: Tipografia do Paiz, 1872.

RELATÓRIO do Presidente da Província do Maranhão, o Doutor João Lustosa da Cunha Paranaguá na abertura da Assemblea Legislativa Provincial no dia 3 de maio de 1859. Maranhão: Typographia J.M.C. de Farias,1859.

RELATÓRIO que o Exmo. Snr. Presidente da Província do Maranhão, o Doutor Lafayette Rodrigues Pereira apresentou à Assemblea Legislativa Provincial no dia 3 de maio de 1866. Maranhão: Typographia J.M.C. de Farias,1866. 
VIVEIROS, J. Benedicto Leite: um verdadeiro republico. 2. ed. São Luís: Departamento de Imprensa Nacional,1960. 
ARTIGO 


\section{César Augusto Castro}

Professor Adjunto do Departamento de Biblioteconomia e do Programa de pós-graduação em Educação da Universidade Federal do Maranhão.

Doutor em Educação pela Faculdade de Educação da Universidade de São Paulo-USP.

ccampin@terra.com.br

\section{Ana Luiza Ferreira Pinheiro}

Graduada em Biblioteconomia pela Universidade Federal do Maranhão.

Bibliotecária da Faculdade Atenas Maranhense-FAMA.

analuisa@fama.edu.br

Recebido em: 01/03/2006

Aceito para publicação em: jun. 2006 